\title{
RELAÇÃO SAÚDE-DOENÇA A PARTIR DAS EXPERIÊNCIAS DE VIDA DAS CRIANÇAS
}

\author{
Glenda Gabriele Bezerra Beltrãol \\ José Vicente de Souza Aguiar ${ }^{2}$ \\ Andrigéssica Mota da Silva ${ }^{3}$
}

\section{RESUMO}

Discussões sobre educação em saúde são urgentes e devem abranger tanto escolas quanto espaços não-escolares, a fim de que as crianças possam ter reflexões essenciais acerca de assuntos que influenciam na sua vida e, consequentemente, na sua saúde. Buscou-se compreender como a temática saúde-doença se relaciona às experiências de vida das crianças do $5^{\circ}$ ano do Ensino Fundamental de uma escola estadual da cidade de Barreirinha, Amazonas. A pesquisa foi desenvolvida com abordagem e análise de dados de cunho fenomenológico-hermenêutico. A investigação contou com 16 crianças de ambos os sexos, com idade entre dez e onze anos, de uma turma $5^{\circ}$ ano do Ensino Fundamental. Os resultados apontam que as crianças têm conhecimentos da temática saúde-doença e apresentam uma pluralidade de experiências cotidianas de adoecimento (experiências de adoecimento, relacionamento interpessoal, lazer, hábitos de higiene e alimentar) que podem afetar suas vidas e seus desempenhos escolares. Em relação às questões alimentares, contudo, há uma dissociação, em parte, entre o saber adquirido nas aprendizagens escolares e as atitudes de escolhas alimentares, dentre as possíveis por elas. Esta dissociação indica a necessidade de buscar meios que não só contribuam para a aquisição de conhecimentos teóricos, mas que possibilitem aos alunos fazerem articulação no seu cotidiano, principalmente nas escolhas alimentares, sobretudo daqueles menos prejudiciais à saúde. Esse trabalho destaca a necessidade de discussões sobre o tema saúde-doença nos espaços escolares e não-escolares, de maneira a proporcionar aos alunos o acesso aos conhecimentos sobre a relação saúdedoença fundamentais para as suas vidas.

Palavras-chave: Saúde-doença. Experiência de vida. Crianças.

\footnotetext{
1 Mestre em Educação em Ensino de Ciências na Amazônia pelo Programa de PósGraduação em Ensino de Ciências na Região Amazônica - Universidade do Estado do Amazonas - UEA; Fundamentos da Pesquisa em Educação e Ensino de Ciências. ORCID: https://orcid.org/0000-0002-3837-0926. E-mail: glendagabrielebb@gmail.com

2 Doutor em Educação pela Universidade Federal do Rio Grande do SUI-UFRGS, professor da Universidade do Estado do Amazonas, Programa de Pós-Graduação em Educação em Ensino de Ciências na Amazônia, Grupo de pesquisa Fundamentos da Pesquisa em Educação e Ensino de Ciências, Brasil. ORCID: https://orcid.org/0000-0001-7754-1620. E-mail: jvicente@vea.edu.br

3 Mestre em Educação em Ensino de Ciências na Amazônia pelo Programa de PósGraduação em Ensino de Ciências na Região Amazônica - Universidade do Estado do Amazonas - UEA, Grupo de pesquisa Fundamentos da Pesquisa em Educação e Ensino de Ciências. ORCID: https://orcid.org/0000-0001-8862-3453. E-mail:
} andrigessica.mota@gmail.com 


\title{
HEALTH-DISEASE RELATIONSHIP FROM CHILDREM'S LIFE EXPERIENCES
}

\begin{abstract}
Discussions on health education are urgent and should cover both school and nonschool spaces so that children can reflect on essential issues that influence their lives and, consequently, their health. We sought to understand how the health-disease theme relates to the life experiences of children in the 5th grade of Elementary School of a State School in the city of Barreirinha, Amazonas, Brazil. The research was developed with a phenomenological-hermeneutic approach and data analysis. The investigation involved 16 children of both sexes, aged between ten and eleven years, from a 5th grade Elementary School class. The results indicate that children have knowledge of the health-disease theme and present a plurality of daily experiences of illness (experiences of illness, interpersonal relationship, leisure, hygiene and eating habits) that can affect their lives and their school performance. Regarding food issues, however, there is a dissociation, in part, between the knowledge acquired in school learning and the attitudes regarding food choices that are available to them. This dissociation indicates the need to seek means that not only contribute to the acquisition of theoretical knowledge, but that allow students to make articulations in their daily lives, especially in food choices, principally those less harmful to health. This study highlights the need for discussions on the health-disease theme in school and non-school spaces, in order to provide students with access to knowledge about the health-disease relationship fundamental to their lives.
\end{abstract}

Keywords: Health-disease. Life experiences. Children.

\section{RELACIÓN SALUD-ENFERMEDAD A PARTIR DE LAS EXPERIENCIAS DE VIDA DE LOS NIÑOS}

\section{RESUMEN}

Las discusiones sobre educación para la salud son urgentes y deben abarcar tanto los espacios escolares como no escolares, para que los niños puedan tener reflexiones esenciales acerca de asuntos que influyen en su vida $y$, en consecuencia, en su salud. Se buscó comprender como la temática saludenfermedad se relaciona con las experiencias de vida de los niños de $5^{\circ}$ grado de primaria de una escuela estatal de la ciudad de Barreirinha, Amazonas. La investigación se desarrolló con análisis de datos y abordaje fenomenológicohermenéutico. La investigación contó con 16 niños de ambos sexos, con edades entre los diez y once años, de una clase de $5^{\circ}$ grado de primaria. Los resultados indican que los niños tienen conocimientos de la temática salud-enfermedad y presentan una pluralidad de experiencias cotidianas de enfermedad (experiencias de enfermedad, relaciones interpersonales, ocio, hábitos de higiene y alimentación) que pueden afectar sus vidas y sus desempeños escolares. Con relación a las cuestiones alimentarias, sin embargo, existe una disociación, en parte, entre el saber adquirido en los aprendizajes escolares y las actitudes de elecciones alimentarias, entre las posibles de ellas. Esta disociación indica la necesidad de buscar medios que no solo contribuyan para la adquisición de conocimientos teóricos, sino que le permitan a los alumnos hacer articulación en su vida diaria, principalmente en las 
elecciones alimentarias, especialmente aquellas menos perjudiciales para la salud. Este trabajo destaca la necesidad de discusiones sobre el tema salud-enfermedad en los espacios escolares y no escolares, con el fin de proporcionar a los alumnos el acceso a conocimientos sobre la relación salud-enfermedad fundamental para sus vidas.

Palabras clave: Salud-enfermedad. Experiencia de vida. Niños.

\section{INTRODUÇÃO}

A instituição escolar é um espaço de constante interação dos estudantes e configura-se como um local de excelência para as discussões sobre o saber moderno, inclusive para a educação e saúde. É oportuno aproveitar esse espaço.

No cenário brasileiro atual, muitos problemas estão em torno da questão saúde-doença, como problemas ambientais, alimentares e sanitários que têm afetado a saúde da população, sobretudo, das crianças que são as mais vulneráveis a essas situações. O Ministério da Saúde (BRASIL, 2017) tem alertado sobre os altos índices de doenças diarreicas, consideradas a segunda causa de morte de crianças no Brasil. Reforçando essa informação, os dados da Secretaria Municipal de Saúde (SEMSA) do Município de Barreirinha indicam as doenças diarreicas como as que mais afetam as crianças, sobretudo as que moram nas áreas de várzeas, principalmente no período de subida das águas dos rios amazônicos, fenômeno conhecido como enchente amazônica, correspondente aos meses de março até meados de junho, aproximadamente.

Mediante a essas situações, foi desenvolvido o estudo da temática, com o propósito de estabelecer "O entendimento da relação saúdedoença com as experiências de vida de crianças". A partir do conhecimento das condições de saúde delas, principais afetadas por doenças diarreicas. O foco na temática saúde-doença deu-se com vistas às doenças cujas transmissões ocorressem por via oral. Diante disso, este trabalho teve como objetivo compreender como a temática saúde-doença se relaciona com as experiências de vida das crianças do $5^{\circ}$ do Ensino 
Fundamental em uma escola da cidade de Barreirinha do Estado do Amazonas.

Nessa perspectiva, a inserção da educação em saúde no espaço educacional é indispensável, uma vez que pode propiciar conhecimentos sobre saúde-doença de maneira a promover uma reflexão, levando os estudantes a se posicionarem e fazerem escolhas com base em conhecimentos diante de assuntos que interferem nas suas vidas.

Para tanto, considerando que o direito de uma vida com saúde não depende apenas de uma ação de cura implementada pelos saberes do campo da saúde, destaca-se que a discussão no espaço escolar corresponde a uma necessidade fundamental, de modo a despertar nos alunos o compromisso com o seu corpo, consequentemente com sua vida, pois é essencial que eles consigam relacionar os conhecimentos aprendidos na escola às suas experiências de vida. A educação em saúde se torna imprescindível para a articulação de assuntos com vistas à promoção da saúde, entretanto, a abordagem dessa temática pode e deve ser articulada também a outros espaços não escolares, como as relacionadas ao sistema de Saúde Pública.

\section{CONHECIMENTOS RELATIVOS AOS CUIDADOS COM A SAÚDE E A ESCOLA}

Existem vários lugares que se pode estar em contato com $O$ conhecimento, mas a escola configura-se como a instituição mais sistemática, organizada e planejada para que isso aconteça (MOHR, 2002). Nela tem-se contato com os mais diferentes assuntos e conhecimentos científicos que servirão para várias etapas em nossa vida. Aqui se enfatizam os ensinamentos sobre a relação saúde-doença.

O conhecimento, como a capacidade de estabelecer relações para entender os fenômenos, corresponde a uma capacidade exclusiva do ser humano e direito de todos, de extrema relevância para o pensamento sobre as relações sociedade e saber científico. Bachelard (1996, p.17), afirma que "O conhecimento do real é a luz que projeta algumas sombras". O autor coloca em evidência que nunca teremos o privilégio de chegar ao 
conhecimento absoluto da realidade dos fenômenos, pois ele é histórico, passível de retificações, além do mais, existe uma diversidade a conhecer. Sobre essa questão do conhecimento, Merleau-Ponty (2018) relaciona a construção do conhecimento com a forma que percebemos o que nos cerca atribuindo significados ao que foi assimilado pelos sentidos. Assim, entende-se que o conhecimento é construído pela percepção na perspectiva fenomenológica, embora tenha contornos próximos ao apresentado por Bachelard, ou seja, a percepção possui alcances aproximados sobre os fenômenos observados.

Diante disso, possibilitar os alunos situações que os façam refletir e perceber o que acontece no seu cotidiano sobre os assuntos que afetam a saúde e o comportamento dos indivíduos possibilita a aquisição de conhecimentos fundamentais para uma vida menos acometidas por problemas de saúde.

Acredita-se que é indispensável abordar assuntos relativos à saúde das crianças com base no seu cotidiano. Entretanto, pensamos que o desafio maior é fazer com que elas consigam relacionar esses conhecimentos proporcionados na escola com o que acontece no seu cotidiano. Mohr (2002, p. 30) discorre sobre o papel fundamental de "[...] criar mecanismos que permitam ao ser humano fazer uso efetivo deste conhecimento na sua vida".

Essa discussão que Mohr (2002) faz sobre a importância da articulação dos conhecimentos ensinados na escola com o que acontece no cotidiano das crianças é pertinente, pois isso é ainda um grande desafio e uma realidade vivida por muitas pessoas. É visivel que a necessidade de reverter essa situação para que as pessoas consigam relacionar esses conhecimentos aprendidos na escola à sua vida diária. Mohr (2002, p. 26), ainda acrescenta que:

[...] temos, em um processo de saúde-doença no nível individual, pessoas atormentadas por problemas, situações e informações com as quais não conseguem lidar de maneira satisfatória. O mesmo ocorre no nível coletivo: a insegurança, a negligência, a ignorância e a falta de consciência sobre problemas e fatores relacionados à 
saúde pública e a elementos do ambiente físico e social condicionantes do processo saúde-doença, são a regra.

Daí o grande potencial da educação e saúde na escola desde a infância, de maneira a possibilitar o contato com conhecimentos relacionados à sua vida. Mohr (2002, p. 26), afirma que: "Esta é a missão de cidadania que a escola tem a cumprir, permitindo aos indivíduos se apropriarem, compreenderem e agirem no mundo em que vivem".

Assim, os conhecimentos ensinados na escola devem colaborar para que os alunos, ao viverem situações em que precisem tomar decisões de cunho individual e coletivo, sejam capazes de fazer relação com o que aprenderam (KRASILCHIK, 2011). Diante do exposto, a educação em saúde na escola deve propiciar reflexões essenciais sobre assuntos que influenciam na saúde dos indivíduos.

\section{PROCEDIMENTOS METODOLÓGICOS}

O local da pesquisa foi uma escola estadual que atende alunos do $1^{\circ}$ ao $5^{\circ}$ ano do Ensino Fundamental, no município de Barreirinha, Amazonas. A cidade de Barreirinha está situada nas margens do Rio Paraná do Ramos, pertence à Mesorregião do Centro Amazonense e Microrregião de Parintins. Localiza-se ao leste de Manaus, cerca de $330 \mathrm{~km}$ em linha reta e $420 \mathrm{~km}$ por via fluvial. Apresenta extensão territorial de $5.751,00 \mathrm{~km} 2$ (RIBEIRO e CARNEIRO, 2016, p. 2). A população de Barreirinha se caracteriza pela sua formação envolvendo pessoas de raízes indígenas, branca, quilombola dentre outros. Dessa forma, parte da população de Barreirinha tem raízes indígenas, pois o povo Sateré-Mawé é residente histórico nessa região. Existem também muitos afrodescendentes no Município de Barreirinha, que assim como os indígenas reivindicam seus direitos de ancestralidade e buscam fortalecer suas raízes.

Dessa forma, o que mais se destaca no município no contexto cultural consiste na realização, no mês de agosto, da festa em homenagem à padroeira "Nossa Senhora do Bom Socorro", que atrai pessoas de vários 
locais e contribui para a cultura e religião da população. Além da festa da padroeira, a cidade conta com outro atrativo cultural, correspondente a realização, no mês de outubro, do Festival Folclórico dos Touros: Touro Branco e Touro Preto, com foco para os costumes e tradições do povo amazônico.

Outro fator de destaque no Município é a Literatura, uma vez que Barreirinha é conhecida por ser a terra de um dos grandes poetas da literatura brasileira, conhecido como o poeta da floresta, Thiago de Mello. Este escritor teve suas obras traduzidas para mais de trinta idiomas e é conhecido internacionalmente.

No que diz respeito à pesquisa, ela foi realizada em uma turma de 30 crianças, com faixa etária entre 10 e 11 anos de idade do $5^{\circ}$ ano do Ensino Fundamental, dos quais, neste trabalho, os interlocutores foram 16 crianças, de ambos os sexos, que mais se mostraram dispostas a participar das atividades realizadas durante essa investigação, as quais receberam nomes fictícios.

Cabe destacar que grande parte das crianças que fizeram parte desta pesquisa, vivem em um dos bairros periféricos da cidade, em maioria com situação de vulnerabilidade social, além de residirem próximas ao lixão da cidade, o que reforça a necessidade das discussões sobre saúdedoença.

A pesquisa pauta-se em um enfoque qualitativo, uma vez que busca compreender os fenômenos sociais, levando em consideração as experiências de vida das crianças, cuja abordagem e análise é descritiva e interpretativa que prima pela compreensão dos dados (CRESSWELL, 2010, p. 209). O enfoque qualitativo permitiu adentrar nos fenômenos da pesquisa e possibilitou um diálogo e uma compreensão da realidade.

Em se tratando de pesquisa qualitativa, também se utilizou o método de abordagem Fenomenológico. A Fenomenologia como método de abordagem filosófico busca compreender o que determinado fenômeno significa e como ele é experienciado (BICUDO, 2011). No que concerne ao pensamento de Merleau-Ponty (2018, p. 1), em seu livro Fenomenologia da Percepção, "[...] a fenomenologia é também uma filosofia que repõe as 
essências na existência, e não pensa que se possa compreender o homem e o mundo de outra forma senão a partir de sua facticidade". Com isso, criouse estratégias para que as crianças pudessem falar sobre a temática, de modo que o exercício investigativo da interpretação tivesse como foco as experiências delas de ter vivido estados de adoecimento.

Ela é um método filosófico que acontece a partir do que se descreve/analisa, pois prima pela descrição das experiências que temos das coisas de forma direta tal como ela é, na tentativa de compreensão de determinado fenômeno, que neste trabalho se configura como a tentativa de compreensão a partir da temática saúde-doença. Segundo MerleauPonty (2018, p. 5), "[...] O real deve ser descrito, não construído ou constituído. Isso quer dizer que não posso assimilar a percepção às sínteses que são da ordem do juízo, dos atos ou da predicação". Mas a descrição não se restringe a si mesma, não é um ato final do procedimento, ou melhor é um momento da pesquisa, visto que ela será submetida a análises e compreensões.

Esse método de abordagem é pertinente na pesquisa, uma vez que possibilita entender que, por meio do retorno e da descrição da percepção, é possivel encontrar algo de originário. Por isso, na descrição, o retorno às coisas mesmas, ou seja, a experiência concreta é tão essencial, pois busca recuperar o sentido originário antes de qualquer preconceito (MERLEAUPONTY, 2018). Com base nisso, está pesquisa busca pela compreensão dos significados que os sujeitos dão sobre a temática saúde-doença e da forma que eles a experienciam, no intuito de trazer 0 sentido primeiro correspondentes aos mundos vividos pelas crianças a considerar suas experiências de adoecimentos.

As percepções dos sujeitos da pesquisa foram descritas por meio de desenhos, da escrita, da fala, uma vez que a fenomenologia segundo Merleau-Ponty (2018), vai além dos fatos, ela busca conhecer também os sentidos atribuídos pelas sujeitos aos fenômenos vividos. 
A análise de dados na perspectiva fenomenológica é organizada em três fases: descrição, redução fenomenológica e interpretação fenomenológica.

A coleta de dados se deu por meio de roda de conversa, aplicação de oficina com as crianças e observações em consonância com o objetivo desta pesquisa.

\section{OFICINA DE DESENHO: Como as crianças se sentem quando estão com saúde e quando estão doentes}

A oficina de desenho surgiu com o objetivo de conhecer, a partir das respostas e das perspectivas das crianças, representadas por meio do desenho, de como elas se sentem quando estão com saúde e quando estão doentes. Nesta ocasião, a oficina foi organizada em dois momentos, a saber: o primeiro foi uma conversa sobre saúde; o segundo, diz respeito a elaboração do desenho pelas crianças e a socialização sobre o que tinham representado no desenho.

No primeiro momento da oficina, explicou-se para elas o que seria saúde, isto é, o seu significado. Também se realizou uma dinâmica com imagens que buscavam mostrar para as crianças que saúde envolve vários aspectos como o cultural, o social, o mental, o econômico, dentre outros. Apresentou-se também um vídeo sobre a temática para ajudar no processo de ensino e aprendizagem.

Consecutivamente, pediu-se a elas que exprimissem, através de desenhos, como se sentem quando estão com saúde e quando estão doentes. Dutra (2013 p. 74) afirma que "desenhar é a arte gráfica que encanta as crianças e como forma de linguagem possui ampla capacidade de comunicação e expressão". Sendo assim, acreditamos que no desenho a criança revela sua visão de mundo e suas vivências. Dessa maneira, analisou-se a expressão gráfica das crianças tendo como base a perspectiva fenomenológica, apoiada na ideia de que "[...] tudo aquilo que sei do mundo, mesmo por ciência, eu o sei a partir de uma visão minha ou 
de uma experiência do mundo sem a qual os símbolos da ciência não poderiam dizer nada" (MERLEAU-PONTY, 2018, p. 3).

Os primeiros desenhos das crianças (FIGURA 1) representaram como elas se sentem quando estão com saúde e todas socializaram o que cada um representava. Optou-se em transcrever literalmente as interpretações das crianças sobre os desenhos por elas elaborados.

FIGURA 1: Oficina de desenho: "como eu me sinto quando estou com saúde"

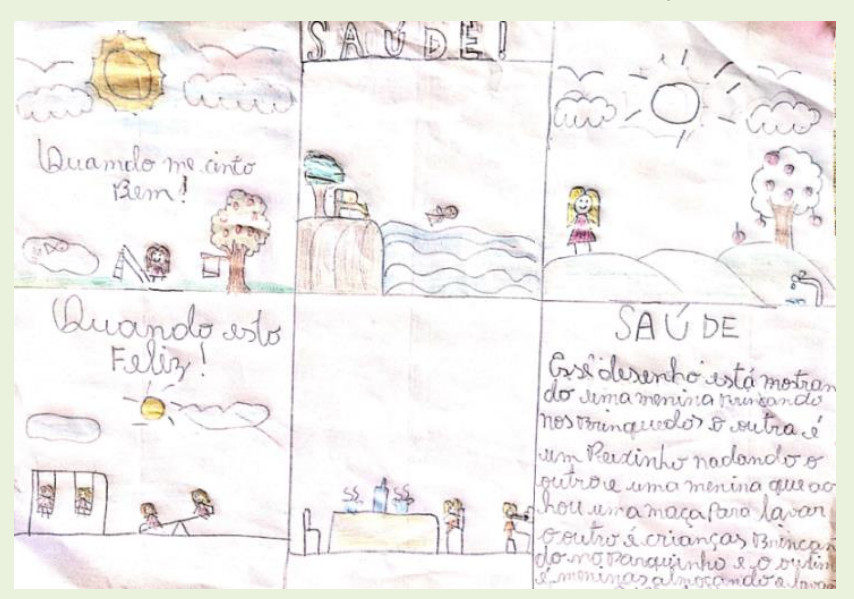

Fonte: Criança 01, 2019.

Esse desenho está mostrando uma menina brincando nos brinquedos, a outra é um peixinho nadando, o outro é uma menina que achou uma maçã para lavar, o outro é criança brincando no parquinho e o outro são meninas almoçando e lavando as mãos (Criança 01,10 anos).

No desenho acima (FIGURA 1), percebeu-se que quando as crianças estão com saúde elas se sentem bem e felizes. Neste desenho, tem-se também a representação, como relatado pela autora, de crianças brincando em um parquinho, de um peixinho nadando, colocando nesse momento em cena os aspectos do meio ambiente, da natureza e dos animais. A autora do desenho revelou um procedimento de cuidado, ao representar "uma menina que achou uma maçã para lavar e meninas almoçando e lavando as mãos". O interessante do desenho da criança 01 é que ela apresentou vários elementos para mostrar como se sente quando está com saúde, revelando que saúde é lazer (uma vez que destacou crianças brincando), é estar bem e feliz. 
Vale destacar que nesse desenho, compreende-se que a autora trouxe cenas do seu cotidiano para representar quando ela está com saúde, o que mostra uma relação da temática saúde-doença com o cotidiano delas, isso porque, alguns elementos no desenho apresentam práticas de cuidado pensando na saúde.

Outro desenho que merece destaque é a arte da criança 02, que, sem colorir o seu desenho, apresenta crianças brincando, conversando e se divertindo, conforme a Figura 2):

FIGURA 2: Oficina de desenho: "como eu me sinto quando estou com saúde"

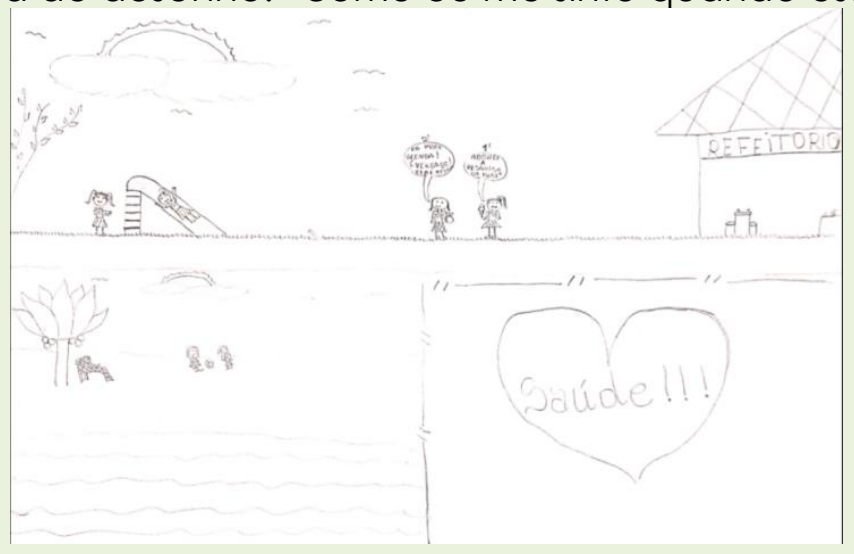

Fonte: Criança 02, 2019.

Para mim saúde é uma das coisas mais importantes que devemos ter, pois sem saúde não somos nada. Devemos valorizar a saúde enquanto temos ela, porque tem várias pessoas que necessitam de saúde. Quando estou com saúde gosto de brincar, estudar, conversar, comer, dormir e me divertir (Criança 02, 11 anos).

A criança 02, nesse desenho, retratou o que ela gosta de fazer quando está se sentido com saúde, como brincar no escorregador, conversar no refeitório da escola e dormir. Assim, notou-se de acordo com o relato da autora do desenho que ela sabe do papel fundamental da saúde para a vida e a importância de valorizá-la. Por meio do desenho, percebeu-se que a criança interliga grande parte das suas experiências diárias com aquilo que ela se sente quando está com saúde. 
Observou-se, no desenho da criança 03 (FIGURA 3), meninas jogando bola, pulando no rio e elementos da natureza como o sol que aparece em todas as representações dessa autora, além de uma árvore.

FIGURA 3: Oficina de desenho: "como eu me sinto quando estou com saúde"

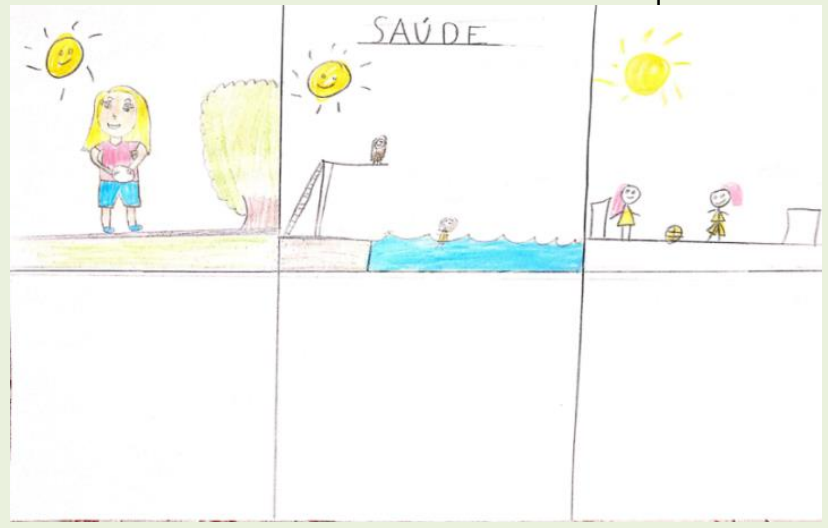

Fonte: Criança 03, 2019.

Eu desenhei vários desenhos que indicam como eu me sinto quando estou com saúde (Criança 03, 10 anos).

Ela iniciou apresentando informações das atividades que ela gosta de fazer, ou seja, do seu contexto como: brincar de bola, pular na água, o que denota que quando ela está se sentido com saúde gosta de atividades de lazer, de se divertir e que se sente bem disposta. Sinalizou a presença de elementos presentes na natureza como o sol, a árvore e o rio e retomou por duas vezes, a imagem de crianças com uma bola, demonstrando que é uma das suas atividades favoritas.

Quanto ao desenho da criança 04 (FIGURA 4), percebeu-se que ela representou o jogo de futebol, que é uma das atividades que gosta de fazer quando está com saúde e feliz. 
FIGURA 4: Oficina de desenho: "como eu me sinto quando estou com saúde"

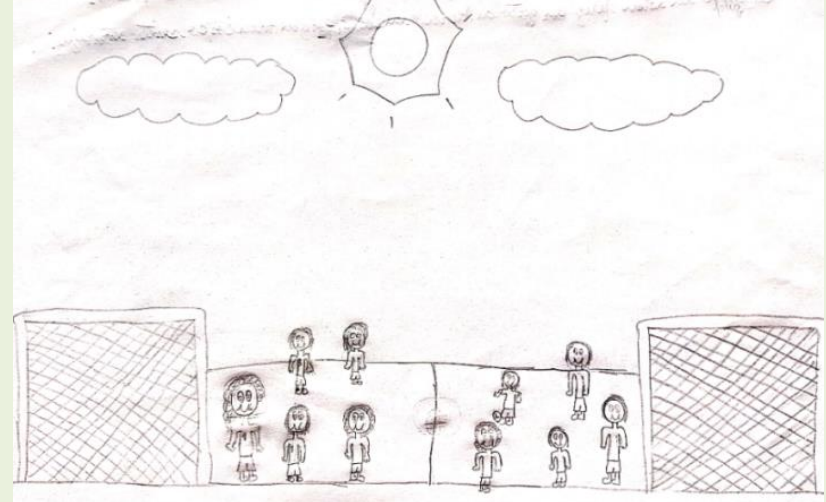

Fonte: Criança 04, 2019.

Quando estou feliz eu gosto de brincar de bola, porque meu corpo sente energia (Criança 04, 11 anos).

A criança 04, na ilustração e na socialização do que desenhou revela que quando está com saúde, o corpo dela sente energia, isto é, ele tem força para brincar de bola, se sente disposta e feliz para prática atividades. Mostrou também um certo entendimento no que diz respeito à saúde, ao retratar "porque meu corpo sente energia".

Diante do exposto, compreende-se que a maioria das crianças que integraram essa pesquisa, evidenciaram no seu desenho "como eu me sinto quando estou com saúde" vinculado ao lazer (brincar) e autocuidado (higiene, alimentação saudável), os quais proporcionam ao ser humano um bem-estar. Percebeu-se que, em todos os desenhos, o brincar era a atividade mais mencionada e que a compreensão delas acerca de como elas se sentem quando estão com saúde foi baseada nas suas experiências, pois é a partir das experiências que é possível associar, denominar e atribuir significados a tudo que foi percebido no decorrer de um determinado momento (MERLEAU-PONTY, 2018). Além disso, percebeu-se poucas vezes, de modo não muito evidente, que elas articulam os conhecimentos sobre saúde-doença às suas experiências de vida.

No que tange ao segundo desenho, que representa como as crianças se sentem quando estão doentes, a criança 02 desenhou (FIGURA 5) três 
cenas diferentes. A primeira cena é uma criança deitada na cama, a segunda cena é uma criança na mesa com a alimentação, e a última cena, são duas crianças em uma praça

Figura 5: Oficina de desenho: "como eu me sinto quando estou doente"

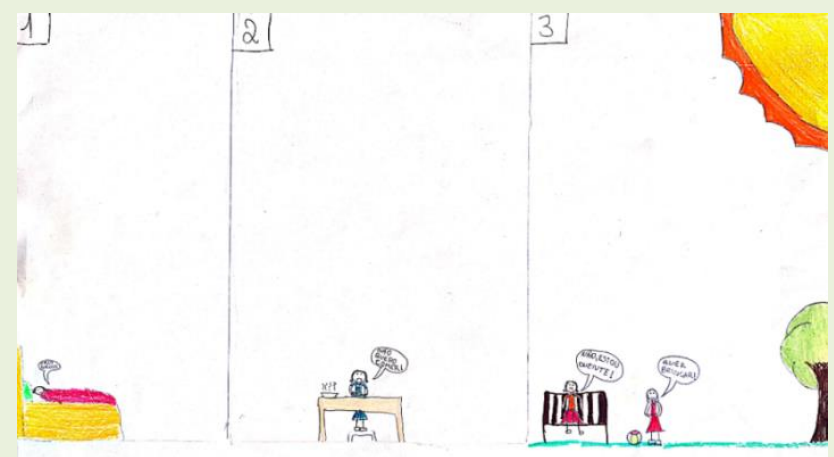

Fonte: Criança 02, 2019.

1- Eu na cama com dor; 2- Não quero comer; 3- Não quero brincar (Criança 02, 11 anos).

Como pode-se ver, a autora do desenho (FIGURA 5), retratou três momentos de como ela se sente quando está doente, e que é muito comum nessa situação, os quais ela identificou como "eu na cama com dor", e no segundo episódio, recusando a alimentação, e algo que na última cena foi identificado como não querer brincar. As crianças quando estão doentes, na grande maioria das vezes, perdem até a vontade de brincar nessa fase, atividade que é a preferida das crianças, visto ser a atividade mais citada quando elas se sentem com saúde. O estado de adoecimento repercute também no desempenho escolar das crianças, visto que ele retira da criança a energia para se envolver com as atividades escolares e os estudos.

O desenho da criança 04 mostra uma pessoa deitada em uma rede, conforme a Figura 6: 
Figura 6: Oficina de desenho: "como eu me sinto quando estou doente"
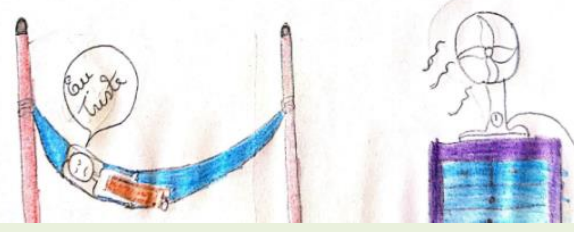

Fonte: Criança 04, 2019.

Eu desenhei uma pessoa doente triste (Criança 04, 11 anos).

Neste desenho (FIGURA 6), o artista desenhou uma pessoa doente deitada em uma rede de descanso, identificando que ela estava triste. A criança, no desenho, permite a visualização da sua forma de estar e ser no mundo naquele exato momento, isso porque, depois ela pode mudar o seu modo de ver e viver o mundo (MERLEAU-PONTY, 2006). Nesse momento, ela revelou que quando está doente se sente triste. O próximo desenho (figura 7) também mostra uma pessoa deitada na cama e outra pessoa, que seria a mãe da criança, indo cuidar da filha doente. Na imagem ainda tem uma árvore e um sol.

Figura 7: Oficina de desenho: "como eu me sinto quando estou com doente"

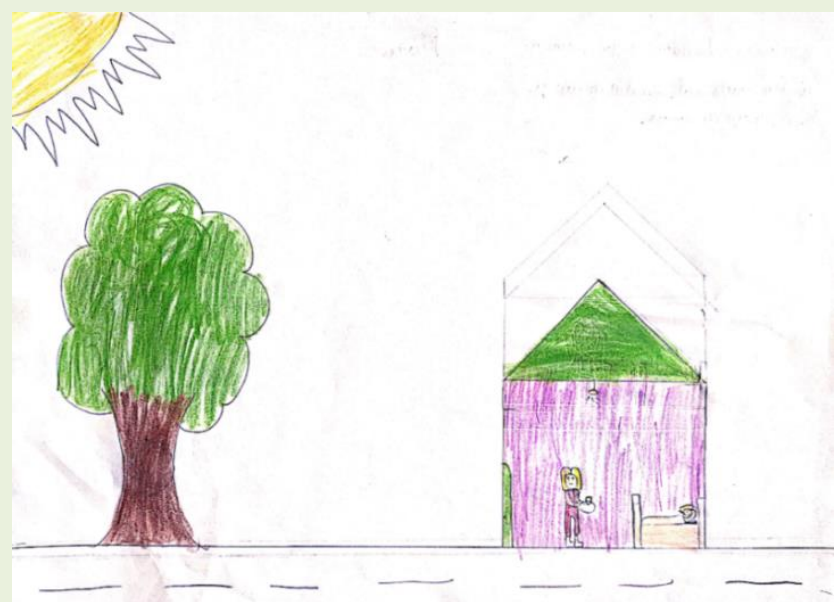

Fonte: Criança 06, 2019. 
Quando estou doente fico deitada. Eu fico muito mal com dor de cabeça. Eu descanso na cama (Criança 06, 10 anos).

De acordo com a fala da criança 06, ela se sente mal, com dor de cabeça quando está doente e costuma descansar na cama, explicitando que já teve dor de cabeça nas suas experiências de adoecimento.

O desenho (FIGURA 08), também expressa que a criança 07 se sente triste, chora e fica de cama, indo até o hospital quando está doente. É importante salientar que há mais cinco desenhos que mencionam o hospital no que concerne à doença, mas que não foram colocados neste trabalho, pois tentou-se fazer a escolha por categoria e escolheu-se esse desenho (FIGURA 8), para os representar. Vejamos:

Figura 8: Oficina de desenho: "como eu me sinto quando estou doente"

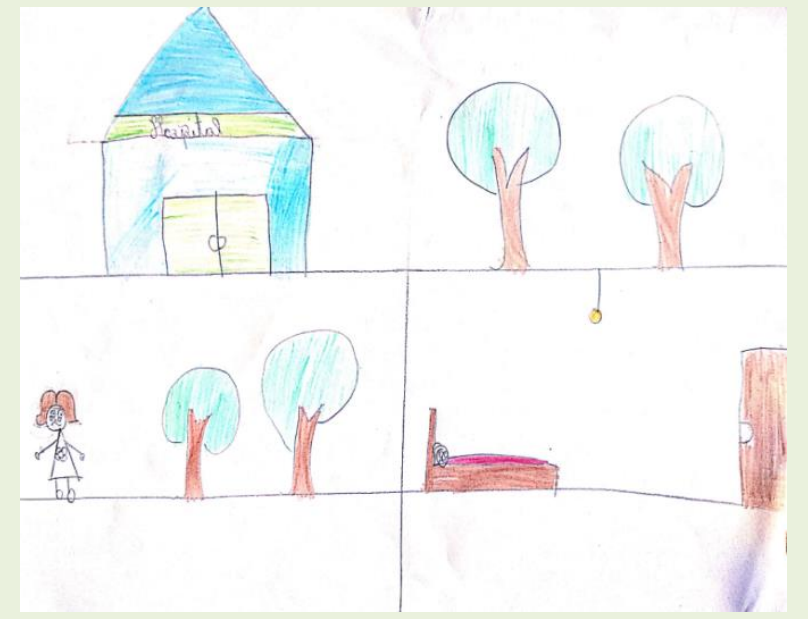

Fonte: Criança 07, 2019.

Eu me sinto triste, choro, fico de cama (Criança 07, 10 anos).

Como se pode ver, o sentimento de tristeza é muito externado pelas crianças quando se sentem doentes, e algumas, como é o caso dessa autora do desenho, até choram quando passam por essa experiência desagradável. Ficar deitada na cama é algo comum quando se está doente e que também foi expresso por algumas crianças. Analisou-se que a compreensão das crianças acerca de como elas se sentem quando estão doentes não é uma compreensão teórica, pois elas expressam fatos 
correspondentes às suas experiências no mundo vivido, de quem já precisou recorrer ao tratamento de saúde hospitalar como representado no desenho.

Com isso, compreende-se através do desenho e da fala das crianças que a doença está relacionada à tristeza e à incapacidade de realização de atividades rotineiras (comer, brincar, interagir com outras crianças e familiares, por exemplo). Por certo, essas respostas demonstraram que essas crianças experenciaram estados de adoecimento.

Assim, os desenhos mostraram as vivências, os anseios, os significados de como as crianças se sentem quando estão doentes, haja vista que neles elas expressaram aquilo que percebem das coisas, o que foi significativo, a sua percepção. Merleau-Ponty (2018, p 513) descreve que, no desenho, a criança parte do significado "Isso quer dizer que minha construção gráfica não é, assim como os traços que a criança acrescenta arbitrariamente ao seu desenho, e que a cada vez subvertem sua significação ("é uma casa, não, é um barco, não, é um velhinho"). Desse modo, o desenho coloca em cena a interação da criança com o outro, com o mundo e traz à realidade um ato de sua percepção mediante às suas experiências de vida (BARROSO, 2017).

Além disso, os desenhos evidenciaram que as crianças têm forte relação com a temática saúde-doença no seu cotidiano. Diante disso, acredita-se que é primordial a abordagem dessa discussão em todos os níveis da educação básica.

\section{RELAÇÃO DO QUE É APRENDIDO NA ESCOLA SOBRE SAÚDE-DOENÇA NAS EXPERIÊNCIAS DE VIDA DAS CRIANÇAS}

Em uma das aulas de Ciências Naturais cedidas pela professora, realizou-se uma roda de conversa com as crianças com a intenção de compreender se faziam relação do que foi aprendido na escola sobre saúde-doença com as suas experiências de vida. Para isso, as rodas de conversa ocorreram em duas oportunidades, ou seja, em dois dias. Cada uma delas foi guiada por uma temática, na qual se procurou explicar e discutir sobre a relação saúde-doença. 
Com a roda formada na sala de aula, iniciou-se uma discussão explicitando para as crianças acerca dos hábitos de higiene e alimentares, seguido de uma revisão do conceito de saúde. Quando foi exibido um vídeo educativo denominado "alimentos e nutrientes" e realizada uma dinâmica com imagens sobre a temática em questão, de modo a estimular a discussão. Com a autorização para utilizar equipamento gravador de voz, colocou-se esse aparelho no centro da roda para ajudar nos registros. A partir de então a conversa começou a se desenvolver, pois foi explicado para as crianças que elas podiam falar a qualquer momento, uma de cada vez. Um dos diálogos consistiv em falar dos hábitos de higiene.

\footnotetext{
Pergunta: Você adota algum procedimento após ir ao banheiro, como lavar as mãos?

Criança 09 (10 anos) eu lavo, mas as vezes eu tenho preguiça de mexer na água.

Criança 10 (10 anos) lavo as vezes.

Criança 01 ( 10 anos) lavo, nem todas as vezes.

Criança 11 (11 anos) sim, sempre.

Criança 12 (10 anos) sim e antes de comer também.

Criança 13 (11 anos) sim, lavo sempre.

Criança 08 ( 10 anos) lavo todas as vezes que vou no banheiro.

Criança 02 ( 11 anos) sim, toda vez.

Criança 14 (10 anos) toda vez.

Criança 07 (10 anos) sim

Criança 15 (10 anos) sim (falou com entusiasmo).

Criança 04 (11 anos) hurum, sempre.

Criança 16 (11 anos) às vezes (DIÁRIO DE CAMPO, OUTUBRO DE 2019).
}

Diante desse diálogo, as crianças relataram lavar as mãos após ir ao banheiro. Entretanto, ainda se ouviu relatos de crianças que nem sempre tem esse hábito, pois ficam com "preguiça de mexer na água". O ato de lavar as mãos também foi observado no momento da merenda, onde se observou que poucas crianças lavavam as mãos antes da merenda na escola. Esse fato é importante de ser destacado, uma vez que não praticar esse ato após ir ao banheiro e antes da alimentação pode ser propício para a contaminação dos alimentos consumidos e, por consequência, para o aparecimento de doenças. Esses conhecimentos sobre hábitos de higiene não são ensinados só na escola. Muitas vezes, as famílias também os 
ensinam às crianças. Porém, cabe destacar que não são todas as famílias que buscam discutir ou ensinar para os filhos hábitos que são essenciais para a vida, deixando à escola essa responsabilidade. A escola necessita contar com a parceria dos familiares no processo de escolarização das crianças. Cabe destacar que o compromisso da escola não se restringe a ensinar a ideia de higiene pessoal às crianças, pois não é esse o seu foco principal.

Em um dos diálogos perguntou-se às crianças sobre o hábito de lavar os alimentos:

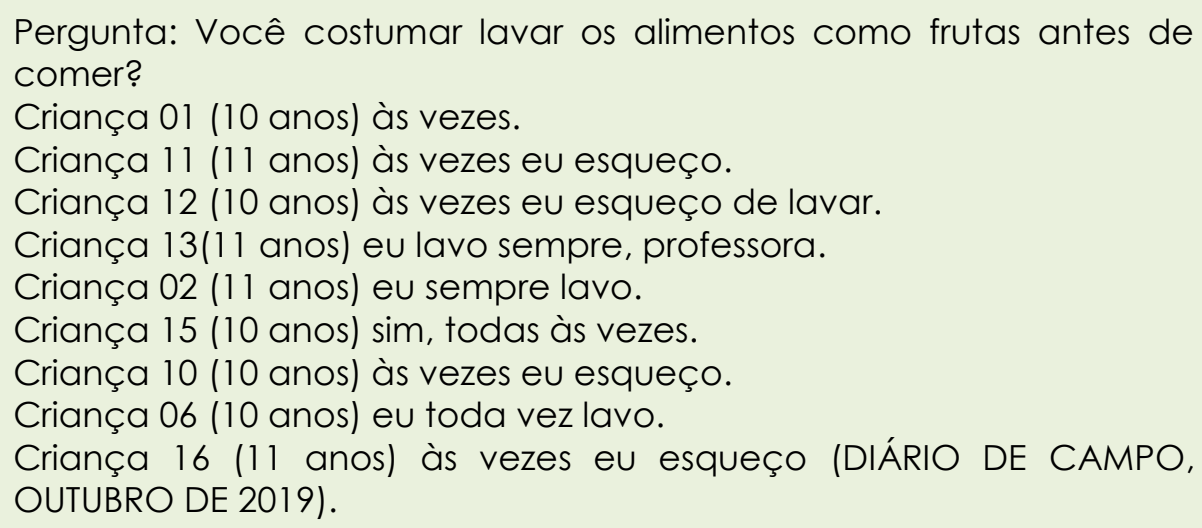

Os relatos apontam que a lavagem de mão não é um ato frequente, tampouco dos alimentos consumidos, visto que a resposta como "às vezes eu esqueço" foi mencionada recorrentemente no diálogo. O que se percebe é que as crianças que disseram lavar sempre os alimentos correspondem as que os pais/responsáveis mais participam das atividades da escola. O que demonstra a relação entre o acompanhamento dos filhos pelos pais/responsáveis e os cuidados com a higiene por elas assimilados às suas vidas, e que pode refletir na atitude e aprendizagem dos alunos. Por isso que é fundamental a participação dos pais/responsáveis na vida escolar de seus filhos e a parceria da família com a escola.

Em um outro dia, realizou-se a segunda roda de conversa, dando sequência no conteúdo que vinha sendo trabalhado pela professora, tecendo explicações sobre a temática: "Os alimentos e Nutrientes", para suscitar o início do diálogo com as crianças. Ao mesmo tempo foi realizado um diálogo levando em consideração a saúde como bem estar social e 
prática de lazer. Assim direcionou-se a primeira pergunta acerca das escolhas dos alimentos:

Pergunta: Quais os critérios que usam para escolher os alimentos, por que são nutritivos e fazem bem para sua saúde ou porque são bonitos e gostosos?

Criança 01 (10 anos): porque são gostosos.

Criança 12 (10 anos): é a minha mãe que coloca para mim. Ela coloca só "verdura"!

Criança 15 (10 anos): na maioria das vezes eu escolho porque é gostoso e às vezes também porque vai fazer bem para a saúde.

Criança 09 (10 anos): eu escolho o que é melhor para a minha saúde, mas às vezes dá aquela "recaída".

Criança 16 (11 anos): porque ele é gostoso (DIÁRIO DE CAMPO, OUTUBRO DE 2019).

As respostas das crianças quanto à escolha dos alimentos variam. Algumas crianças afirmam escolher o alimento pensando na relação com o nutriente que ele possui, o que pode indicar uma compreensão do papel dos nutrientes na alimentação e para a sua saúde, uma vez que as respostas apresentavam a justificativa "o que faz bem para a saúde". Outras crianças escolhem pelo sabor, pois preferem os que são mais gostosos, o que denota que também existem crianças que não fazem relação com o que é ensinado sobre saúde-doença nas suas experiências. Diante disso, pode-se constatar que as respostas nesse diálogo ficaram divididas, uma vez que algumas crianças afirmaram escolher os alimentos pelo seu valor nutritivo, outras afirmaram escolher com base no sabor do alimento.

Ainda na roda de conversa, indagou-se às crianças se elas costumavam ter momentos de lazer (passear, brincar, sair de casa para algum lugar que não fosse a escola?

Pergunta: Vocês costumam ter momentos de lazer: passear, brincar, sair de casa para algum lugar que não seja a escola?

Criança 06 ( 10 anos) às vezes sim professora.

Criança 13(11 anos) sim. Mais no final de semana.

Criança 02 ( 11 anos) a gente vai às vezes para o Andirá.

Criança 11 ( 11 anos) eu brinco sempre!

Criança 10 (10 anos) eu brinco e às vezes a gente sai.

Pesquisadora: Mas vocês convidam seus pais para ter esses momentos de lazer?

Criança 06 (10 anos) sim.

Criança 13(11 anos) toda vez.

Criança 02 (11 anos) convido, professora.

Criança 11 (11 anos) só às vezes. 
Criança 10 (10 anos) "aham", às vezes porque ela trabalha (DIÁRIO DE CAMPO, OUTUBRO DE 2019).

Nesse diálogo, pode-se assinalar que as crianças relatam ter momentos de lazer e que afirmam, às vezes, convidam os pais para ter esses momentos com elas, o que mostra uma relação de saúde-doença nas suas experiências, uma vez que o conceito de saúde envolve essa perspectiva do lazer (SANTOS, 2014).

De modo geral, diante dos depoimentos das crianças na roda de conversa, nas questões que envolvem saúde como bem estar social e com o lazer, são os momentos que mais vemos a relação das crianças com a temática. Essas crianças que conseguem relacionar os conhecimentos aprendidos nas suas vivencias, são sobretudo, as que os pais/responsáveis participam de forma efetiva da vida escolar. De acordo com Melo et al. (2017, p. 2) "os pais possuem importante papel na formação do hábito alimentar infantil".

Nas questões que envolveram as perguntas acerca dos hábitos de higiene, alimentar, entende-se que as crianças demonstram ter conhecimentos sobre esses assuntos, pois relataram que costumam lavar as mãos após ir ao banheiro, mas que, às vezes, esquecem de lavar os alimentos antes de comer. Tudo isso indica que elas, de certa forma, possuem conhecimentos, e que, por vezes, de acordo com seus relatos, aplicam à vida. Todavia, no que se refere à alimentação, os conhecimentos construídos na escola, não são determinantes na hora de fazer as escolhas alimentares, o que podem comprometer a sua saúde. Isso mostra a necessidade de buscar meios que não só contribuam para a aquisição de conhecimentos, mas que possibilitem aos alunos fazerem articulação ao seu dia a dia.

\section{CONSIDERAÇÕES FINAIS}

Percebe-se cada vez mais a necessidade de discussões nas escolas e nos espaços não escolares acerca da educação em saúde, de modo a 
contribuir para estreitar a relação entre os conhecimentos construídos na escola com as experiências de vida das crianças. Isso tem se tornado emergente mediante o aumento na frequência de doenças ocasionadas pelo consumo de alimentos com alto teor de sódio, de açúcar, de gordura e com conservantes, o que exige, por parte da população, acesso aos conhecimentos que possam nortear suas escolhas, além das doenças de veiculação hídrica, que estão relacionadas às condições de saneamento e de distribuição de água potável na cidade onde se realizou a pesquisa. Assim, articular os conhecimentos sobre saúde-doença às experiências cotidianas têm se tornado fundamental para os cuidados com a vida de uma parcela expressiva da sociedade.

Sob essa perspectiva e diante das reflexões foi possível compreender que as crianças tecem frequentemente relações entre os fenômenos de saúde-doença e o seu cotidiano, uma vez que apresentaram uma pluralidade de experiências envolvendo a temática. Isso porque os estudantes vivenciam diariamente situações que podem afetar suas vidas, sobretudo pelas condições sanitárias onde vivem.

Nos questionamentos acerca dos hábitos de higiene e hábito alimentar, os resultados apontaram que as crianças possuem conhecimentos, uma vez que reconheceram a importância dos atos de lavar as mãos após irem ao banheiro, embora, às vezes, esqueçam de lavar os alimentos antes de comê-los. Tudo isso indica que elas têm conhecimentos sobre essas questões e que, por vezes, de acordo com seus relatos, aplicam à vida. Entretanto, cabe destacar que nas escolhas alimentares, os conhecimentos aprendidos na escola sobre alimentos e nutrientes não são aplicados, tendo em vista que não são determinantes na hora de fazer uma escolha criteriosa do que comer.

Diante disso, considera-se que abordar o tema da saúde na escola, discutir o que é saúde e ressaltar o papel da alimentação para a vida é fundamental, de modo que passem a ter conhecimentos necessários para analisarem os seus hábitos alimentares. 
Os resultados aqui apresentados mostram a necessidade de discussões sobre a saúde-doença com crianças, pais e professores, sobretudo, diante desse cenário que o mundo todo vivencia com a pandemia do novo Coronavírus (COVID-19), que já ceifou 256.504 mil vidas no Brasil e no 2.461.436 no mundo, até o dia 22 de fevereiro de 2021, o que chama atenção a necessidade da discussão temática saúde doença nas escolas e nos espaços não escolares, de modo que os alunos possam refletir sobre os cuidados com a saúde, visto que a população como um todo necessita tomar decisões e agir com base em conhecimentos científicos pensando no bem coletivo, ao mesmo tempo, possa reconhecer e exigir o compromisso do Estado para com a saúde pública.

\section{REFERÊNCIAS}

BRASIL. Ministério da Saúde. Sistema Único de Saúde (SUS), 2017.

BACHELARD, G. A formação do espírito científico: contribuição para uma psicanálise do conhecimento. RJ: Contraponto, 1996.

BARROSO, H. O zoológico do CIGS e o Ensino de Ciências na Amazônia. Dissertação (Mestrado). Universidade do Estado do Amazonas-UEA, MANAUS: UEA, 2017.

BICUDO, M. A. V. Capítulo 3 Pesquisa qualitativa fenomenológica: interrogação, descrição e modalidades de análises. Editora Cortez, São Paulo, 2011.

CRESWELL, J. W. Projeto de Pesquisa: Métodos Qualitativo, Quantitativo e Misto. $3^{a}$ ed., Porto Alegre: Artmed, 2010.

DUTRA, M. A. Entre o grafismo e oralidade: uma interpretação do imaginário da criança ribeirinha amazônica. Manaus: UFAM/ICHL, 2013.

KRASILCHIK, M. Prática de Ensino de Biologia. São Paulo: Edusp, 2011.

MELO, M. K. et al. Influência do comportamento dos pais durante a refeição e no excesso de peso na infância. Escola Anna Nery, 2017; 21 (4): e 20170102.

MERLEAU-PONTY, M. Fenomenologia da percepção. Tradução Carlos Alberto Ribeiro de Moura. - 5a.ed. São Paulo: Editora WMF Martins fontes, 2018. 
MERLEAU-PONTY, M. Psicologia e Pedagogia da Criança. São Paulo. Martins Fontes. $1^{\mathrm{a}}$ edição, 2006.

MOHR, A. A natureza da Educação em Saúde no Ensino Fundamental e os professores de Ciências. Tese (doutorado). Centro de Ciências da Educação, Universidade Federal de Santa Catarina, 2002. $410 f$.

RIBEIRO, P. A.; CARMEIRO, K. K. C. Impactos socioeconômicos e ambientais da enchente e vazante na cidade de Barreirinha (AM). $4^{\circ}$ Encontro Internacional de Política Social. $11^{\circ}$ Encontro Nacional de Política SocialTema: Mobilidade do capital e barreiras às migrações: desafios à Política Social. Vitória (ES, Brasil), 6 a 9 de junho de 2016.

SADALA, M.L.A. A fenomenologia como método para investigar a experiência vivida: uma perspectiva do pensamento de Husserl e de Merleau-Ponty. In: Seminário internacional de pesquisa e estudos qualitativos, Bauru. Anais. Bauru: Universidade do Sagrado Coração de Jesus e Sociedade de Estudos e Pesquisa Qualitativa, 2004.

SANTOS, M. E. T. dos. Tema Transversal Saúde nos Anos Iniciais da Educação Básica: um estudo em escolas com baixo IDEB. Dissertação do Mestrado do Programa de Pós-Graduação em Educação em Ciências: Química da Vida e Saúde da Universidade Federal de Santa Maria-UFSM, RS, 2014.

Recebido em: 22 de setembro de 2020 . Aprovado em: 14 de março de 2021. Publicado em: 26 de abril de 2021.

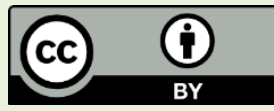

